\title{
Does participation in a pain course based on the International Association for the Study of Pain's curricula guidelines change student knowledge about pain?
}

\author{
Jenny Strong PhD MOccThy BOccThy, Pamela Meredith BA(Hons) BSc BOccThy, \\ Ross Darnell PhD MSc Dip Biom BAppSc, Marlene Chong BA(Hons), Patricia Roche PhD BSc(Hons) MSc Psych
}

\begin{abstract}
J Strong, P Meredith, R Darnell, M Chong, P Roche. Does participation in a pain course based on the International Association for the Study of Pain's curricula guidelines change student knowledge about pain? Pain Res Manage 2003;8(3): $137-142$.
\end{abstract}

BACKGROUND: The People in Pain course was set up as a joint initiative of the Departments of Occupational Therapy and Physiotherapy within the School of Health and Rehabilitation Sciences at The University of Queensland. It was instigated in response to the publication of Pain Curricula for Occupational Therapy and Physiotherapy by the International Association for the Study of Pain (IASP) in 1994 (1). The first year it was offered, the "People in Pain" course comprised $14 \mathrm{~h}$ of lecture content. It was then expanded to encompass $28 \mathrm{~h}$ of lectures and seminar involvement.

OBJECTIVES: To evaluate the impact of participation in a university pain course that meets the IASP pain curricula guidelines to increase health professional students' knowledge about pain.

METHODS: Students who participated in the People in Pain course over the first three years were invited to complete the Revised Pain Knowledge and Attitudes Questionnaire (R-PKAQ) pre- and postcourse. Data obtained from 22 students in the short course formed a pilot project, and data from 22 students in the longer version of the course were used in the present study.

RESULTS: Examination of the correlation matrix indicated substantial correlations between all R-PKAQ subscales except physiological basis of pain and pharmacological management of pain. In both the pilot project during the first year of the course and the expanded course in the following two years, significant improvement was found in the students' knowledge on five of the six subscales of the R-PKAQ: physiological basis of pain, psychological factors of pain perception, assessment and measurement of pain, cognitivebehavioural methods of pain relief, and pharmacological management of pain. Improvements in the developmental aspects of pain perception subscale failed to reach significance.

CONCLUSIONS: An integrated pain course developed according to the pain curriculum guidelines developed by the IASP resulted in increased student knowledge regardless of the length of the program attended.

Key Words: IASP; Knowledge about pain; Occupational therapy; Pain education; Physical therapy
La participation à un cours sur la douleur, fondé sur les lignes directrices de l'Association internationale pour l'étude de la douleur en matière de programmes de formation modifiet-elle les connaissances des étudiants sur la douleur?

CONTEXTE : Le cours People in Pain a été mis sur pied dans le cadre d'une initiative conjointe des départements d'ergothérapie et de physiothérapie de l'école des sciences de la santé et de la réadaptation de l'université du Queensland, en Australie. Le cours faisait suite à la publication du document Pain Curricula for Occupational Therapy and Physiotherapy par l'Association internationale pour l'étude de la douleur en 1994 (1). Le première année, la formation comptait 14 heures d'exposé puis a finalement atteint 28 heures d'exposé et de séminaire.

OBJECTIF : Évaluer dans quelle mesure la participation à un cours universitaire sur la douleur répondant aux lignes directrices de l'Association en matière de programmes de formation permettait d'accroître les connaissances de futurs professionnels de la santé sur la douleur.

MÉTHODE : Les étudiants qui ont participé au cours People in Pain pendant les trois premières années ont été invités à remplir le questionnaire Revised Pain Knowledge and Attitudes avant et après le cours. Des données fournies par 22 étudiants qui ont assisté à la formule abrégée du cours ont fait l'objet d'un projet pilote et des données fournies par 22 étudiants qui ont assisté à la formule enrichie du cours ont été utilisées dans la présente étude.

RÉSULTATS : L'examen de la matrice de corrélations a révélé l'existence de fortes corrélations entre toutes les sous-échelles du questionnaire sauf en ce qui a trait à la physiologie et à la pharmacothérapie de la douleur. Des améliorations importantes ont été relevées en ce qui concerne les connaissances des étudiants sur cinq des six échelles du questionnaire, soit la physiologie de la douleur, les facteurs psychologiques de la perception de la douleur, l'évaluation et les mesures de la douleur, les méthodes cognitivo-comportementales de soulagement de la douleur et la pharmacothérapie de la douleur, et ce, tant dans le projet pilote la première année que dans le cours enrichi les deux années suivantes. Pour ce qui est de la sixième sous-échelle, celle des aspects du développement de la perception de la douleur, les améliorations ont été non significatives. CONCLUSION : La participation à un cours intégré sur la douleur et conçu suivant les lignes directrices de l'Association en matière de programmes de formation a permis d'accrôitre les connaissances des étudiants, peu importe la durée du cours.

No financial gain or incentives have been provided to the authors for this work

School of Health $\mathscr{E}$ Rehabilitation Sciences, The University of Queensland, Brisbane, Queensland, Australia

Correspondence: Dr Jenny Strong, School of Health $\mathbb{E}$ Rehabilitation Sciences, The University of Queensland, Brisbane, Queensland 4072,

Australia. Telephone +61-7-33651320, fax+61-7-33654383, e-mail J.Strong@mailbox.uq.edu.au 
$\mathrm{D}_{\mathrm{o}}^{\mathrm{e}}$ espite the publication of the seminal gate control theory of pain (2) in 1965 and the escalation in pain research and knowledge since that time, the management of many people with pain by health professionals remains inadequate. Numerous surveys have found not only the continued occurrence of inadequate pain management for children, elderly persons, and people with cancer or postoperative pain $(3,4)$, but also inadequate knowledge of pain management by various health professional groups such as nursing $(5,6)$, occupational therapy (7-10), physiotherapy (11), pharmacy (12) and medicine $(6,13,14)$.

With respect to occupational therapy, Rochman (7) investigated pain knowledge among 201 senior occupational therapy students from four universities in northeastern United States. A large number of students were found to endorse common misconceptions regarding pain, particularly relating to pain etiology. In Canada, Unruh (8) identified areas of pain management poorly understood by undergraduate occupational therapy students in their final year of training, including psychosocial components, assessment and measurement techniques, lifespan issues and pharmacology. Pain knowledge among graduated occupational therapists in Australia and the United States has also been found to be limited, especially in the areas of pain assessment and measurement $(9,10)$, and pharmacological principles of pain management (9).

Improving pain education among health professionals is widely recognized as an important step in reducing the unnecessary suffering of people with pain problems $(4,9)$. The International Association for the Study of Pain (IASP) has developed and disseminated both a core curriculum on pain and a number of curricula for health discipline-specific pain education. Published curricula include medicine, dentistry, nursing, psychology, occupational and physical therapy, and pharmacy (copies of the IASP pain curricula can be obtained from $<$ http://www.iasp-pain.org $>$ ). The IASP curricula reflect the multidimensional nature of pain by addressing the physiological, physical and psychological components of pain. Educators have been urged to adopt these curricula in undergraduate health professional courses and to evaluate the impact of such pain education on the students' knowledge of pain (15). In reference to the medical curriculum, Poyhia and Kalso (16) suggested that "the practical implications of the use of the curriculum have not been thus far evaluated".

Following the publication of the IASP curriculum for students in occupational or physical therapy (17) in 1994, the School of Health and Rehabilitation Sciences at The University of Queensland developed and introduced an interdisciplinary course on pain in 1998. The course was developed collaboratively by staff from the disciplines of occupational and physical therapy, and was made available to students from all disciplines within the university. The course utilized the occupational therapy and physiotherapy guidelines and objectives for a pain course, and initially consisted of $14 \mathrm{~h}$ of lectures delivered over 14 weeks. Lectures covered topics such as pain as survival, the medical model, epidemiology and sociology of pain, and peripheral and central processing of pain. The course was then expanded to a $28 \mathrm{~h}$ program, which used lectures and interactive student seminars, where students researched and made presentations on topics such as why are people with cancer pain continuing to receive inadequate pain management? The same lecture topics covered in the smaller course were retained, while additional lecture material relating to pain and children, pain in people unable to communicate about their pain and pain in human immunodeficiency virus/acquired immunodeficiency syndrome was added.

To determine if participation in the course made a difference in the students' knowledge and attitudes about pain, and in their attitudes toward people with pain, an examination was made of the knowledge and attitudes held by students' pre- and postcourse attendance. It was hypothesized that students' knowledge about pain would be increased and attitudes modified at the completion of the course.

\section{Procedure}

\section{METHOD}

As part of a class exercise, students were asked to reflect on their knowledge about pain and its management in weeks 1 and 14 of the semester using the Revised Pain Knowledge and Attitudes Questionnaire (R-PKAQ) - a questionnaire tapping pain knowledge and attitudes. Students were invited to code their two questionnaires with the same code for matching purposes before submission on both occasions. Questionnaires were matched before the removal of identifying data. Completion of the questionnaire was voluntary.

\section{Participants}

Pilot: Forty-one students were enrolled in the pain elective course in 1998. Students were from a variety of fields of study, including occupational therapy, physical therapy, dentistry and science. A total of 22 students completed the pre- and postcourse R-PKAQs and submitted both of them to the course coordinator; this represented just over $50 \%$ of the entire class. A further 22 questionnaires were completed and submitted without an identifying code, and were unusable in the statistical analysis.

Study: For the 1999 and 2000 years combined, a total of 35 students undertook the expanded course. Twenty-two of these students completed the pre- and postcourse R-PKAQ, and voluntarily submitted their coded questionnaires to the course coordinator. Students were predominantly drawn from occupational therapy, physical therapy and human movement programs, along with one social work student. This represented a response rate of $63 \%$ of students enrolled in the course.

\section{Instrument}

The original Pain Knowledge and Attitudes Questionnaire (PKAQ), developed by Unruh (8), consisted of 65 items measuring generic knowledge of pain across six subscales: physiological basis of pain, psychological components of pain, assessment and management strategies, lifespan issues, cognitive-behavioural applications and pharmacological management principles. Examples of the items on each scale are listed in Table 1. Participants were required to score each statement on the questionnaire using the following response categories: disagree, uncertain and agree. The original PKAQ has established content validity and reported an internal consistency of 0.65 (Chronbach's alpha) (8). The questionnaire was later 
TABLE 1

Sample items from the subscales of the Pain Knowledge and Attitudes Questionnaire

\begin{tabular}{|c|c|}
\hline Subscale & Item \\
\hline Physiological basis of pain & Pain is always experienced at the site of tissue damage \\
\hline Psychological factors of pain perception & Chronic pain frequently leads to depression \\
\hline Developmental changes in pain perception & Children experience less pain than adults \\
\hline Assessment and measurement of pain & Frequent measurements of acute pain may make pain worse \\
\hline Pharmacological management of pain & Patient controlled analgesia increases risk of addiction \\
\hline Cognitive-behavioural methods of pain relief & Changing a person's patterns of thought may improve coping \\
\hline
\end{tabular}

TABLE 2

Correlation between proportions correct across pilot subscales on the Revised Pain Knowledge and Attitudes Questionnaire - pre- and postcourse proportions combined

\begin{tabular}{|c|c|c|c|c|c|}
\hline & Physiological & Psychological & Developmental & $\begin{array}{l}\text { Assessment and } \\
\text { measurement }\end{array}$ & Pharmacological \\
\hline Physiological basis of pain & 1.00 & - & - & - & - \\
\hline Psychological factors of pain perception & $0.362^{*}$ & 1.00 & - & - & - \\
\hline Developmental changes in pain perception & 0.177 & $0.593^{* *}$ & 1.00 & - & - \\
\hline Assessment and measurement of pain & 0.199 & $0.492^{* *}$ & $0.394^{* *}$ & 1.00 & - \\
\hline Pharmacological management of pain & -0.037 & $0.445^{\star *}$ & $0.282^{\star *}$ & $0.368^{*}$ & 1.00 \\
\hline Cognitive-behavioural methods of pain relief & 0.166 & $0.367^{*}$ & $0.511^{* *}$ & $0.476^{* *}$ & 0.257 \\
\hline
\end{tabular}

${ }^{*}$ Correlation is significant at the 0.05 level (two-tailed); ${ }^{*}$ Correlation is significant at the 0.01 level (two-tailed)

TABLE 3

Correlation between proportions correct across expanded course subscales on the Revised Pain Knowledge and Attitudes Questionnaire - pre- and postcourse proportions combined

\begin{tabular}{|c|c|c|c|c|c|}
\hline & Physiological & Psychological & Developmental & $\begin{array}{l}\text { Assessment and } \\
\text { measurement }\end{array}$ & Pharmacological \\
\hline Physiological basis of pain & 1.00 & - & - & - & - \\
\hline Psychological factors of pain perception & $0.395^{\star *}$ & 1.00 & - & - & - \\
\hline Developmental changes in pain perception & $0.309^{*}$ & $0.488^{* *}$ & 1.00 & - & - \\
\hline Assessment and measurement of pain & $0.449^{*}$ & $0.476^{\star *}$ & $0.449^{* *}$ & 1.00 & - \\
\hline Pharmacological management of pain & $0.346^{*}$ & $0.401^{* *}$ & $0.482^{* *}$ & 0.260 & 1.00 \\
\hline Cognitive-behavioural methods of pain relief & $0.458^{* *}$ & $0.409^{* *}$ & 0.295 & 0.105 & $0.424^{\star *}$ \\
\hline
\end{tabular}

${ }^{*}$ Correlation is significant at the 0.05 level (two-tailed); ${ }^{* *}$ Correlation is significant at the 0.01 level (two-tailed)

revised by Unruh, who eliminated two items and added four new items (unpublished data, 9). The R-PKAQ, consisting of 69 knowledge items, was used in the present study. Participants scored each item as strongly disagree, disagree, uncertain, agree and strongly agree.

\section{RESULTS}

Data from the 1998 pilot cohort and the 1999 and 2000 cohorts are presented below. Data from the 1999 and 2000 cohorts were pooled for analyses and shall be called the 'expanded course' cohort for clarity. Both the Statistical Package for the Social Sciences version 10.1 (SPSS Inc, USA) and the R statistical package (18) were used for data analyses.

R-PKAQ subscale correlations

A correlation analysis was conducted on the proportions of items correctly answered before and after both the pilot and the expanded courses to examine associations among the six subscales of the R-PKAQ. This analysis was also repeated for the combined sample.

The correlation coefficients between the subscales for the pilot course are presented in Table 2. Results of this analysis indicated that many scales were moderately correlated. The physiological subscale is the notable exception. This scale was significantly correlated only with the psychological subscale and not with any other. The only other subscales not significantly correlated were the pharmacological management of pain with the cognitive-behavioural methods of pain relief subscales. In all, only the correlations between five subscales did not reach significance.

This information was also sought for the expanded course cohort (Table 3). Again, most of the subscales were moderately and significantly positively correlated, with only three not reaching significance. All three were different to the findings for the pilot cohort: the assessment and measurement subscale was not significantly correlated with either the pharmacological 
TABLE 4

Correlation between proportions correct across the pilot and expanded course subscales on the Revised Pain Knowledge and Attitudes Questionnaire - Pre- and postcourse proportions combined

\begin{tabular}{|c|c|c|c|c|c|}
\hline & Physiological & Psychological & Developmental & $\begin{array}{c}\text { Assessment \& } \\
\text { measurement }\end{array}$ & Pharmacological \\
\hline Physiological basis of pain & 1.00 & - & - & - & - \\
\hline Psychological factors of pain perception & $0.406 * *$ & 1.00 & - & - & - \\
\hline Developmental changes in pain perception & $0.254^{*}$ & $0.531^{* *}$ & 1.00 & - & - \\
\hline Assessment and measurement of pain & $0.371^{* *}$ & $0.508^{\star *}$ & $0.418^{\star *}$ & 1.00 & - \\
\hline Pharmacological management of pain & 0.211 & $0.428^{* *}$ & $0.393^{* *}$ & $0.320^{* *}$ & 1.00 \\
\hline Cognitive-behavioural methods of pain relief & $0.379^{* *}$ & $0.463^{* *}$ & $0.384^{\star *}$ & $0.297^{\star *}$ & $0.370^{* *}$ \\
\hline
\end{tabular}

${ }^{*}$ Correlation is significant at the 0.05 level (two-tailed); ${ }^{* *}$ Correlation is significant at the 0.01 level (two-tailed)

TABLE 5

Mean percentage correct, mean pretest scores, mean post-test scores and the SD for each of the subscales on the Revised Pain Knowledge and Attitudes Questionnaire for the 1998 pilot sample

\begin{tabular}{|c|c|c|c|c|c|c|}
\hline & $\begin{array}{c}\text { Average \% correct } \\
\text { (pretest) }\end{array}$ & $\begin{array}{c}\text { Mean } \\
\text { pretest scores }\end{array}$ & $\begin{array}{l}\text { Pretest } \\
\text { SD }\end{array}$ & $\begin{array}{l}\text { Average \% correct } \\
\text { (post-test) }\end{array}$ & $\begin{array}{c}\text { Mean } \\
\text { post-test scores }\end{array}$ & $\begin{array}{l}\text { Post-test } \\
\text { SD }\end{array}$ \\
\hline Physiological basis of pain & 75.45 & 7.55 & 1.29 & 84.09 & 8.41 & 1.22 \\
\hline Psychological factors of pain perception & 73.70 & 10.32 & 2.17 & 83.12 & 11.64 & 1.18 \\
\hline Developmental changes in pain perception & 64.55 & 6.45 & 2.63 & 71.82 & 7.18 & 2.50 \\
\hline Assessment and measurement of pain & 39.55 & 3.96 & 1.56 & 50.91 & 5.09 & 1.34 \\
\hline Pharmacological management of pain & 31.52 & 4.73 & 1.88 & 45.15 & 6.77 & 2.62 \\
\hline Cognitive-behavioural methods of pain relief & 69.09 & 6.91 & 1.27 & 78.18 & 7.82 & 1.22 \\
\hline Total for the R-PKAQ & 58.98 & 39.91 & 7.52 & 68.88 & 46.91 & 5.88 \\
\hline
\end{tabular}

R-PKAQ Revised Pain Knowledge and Attitudes Questionnaire

or the cognitive-behavioural subscales, and the cognitivebehavioural subscale was also not significantly correlated with the developmental subscale.

A correlation analysis on the combined sample of students from the three years of the course revealed that all subscales were significantly positively correlated except for the physiological and pharmacological subscales (Table 4).

Results for the pilot group

The mean percentages for pretest and post-test scores, and the means and SDs for each subscale for the 1998 pilot data presented in Table 5. The pilot group produced pretest total scores that ranged from 25 to 53 , with a mean of 39.91 correct out of 59 . This sample had pretest means that indicated that students were most knowledgeable regarding the physiological basis of pain and the psychological factors of pain perception with an average score of $76 \%$ and $74 \%$ correct, respectively, on these subscales. The students were least knowledgeable concerning the pharmacological management of pain with an average score of $32 \%$ correct on this subscale before completing the pain course.

The pilot group had post-test total scores ranging from 36 to 56 , with a mean of 46.91 correct out of 59 items. As seen in Table 5, improvements in mean test scores occurred across all six subscales. Although students remained least knowledgeable on this subscale, the pharmacological management of pain sub-scale experienced the largest improvement, from a mean of 4.73 pretest to a mean of 6.77 post-test.
Results for the expanded course cohort

Table 6 displays the mean percentage correct of pretest and post-test scores, and the means and SDs for each subscale for the expanded course cohort data. This sample produced pretest total scores ranging from 19 to 51 , with a mean of 34.73 correct out of 59. Pretest means indicated that students were most knowledgeable regarding the physiological basis of pain with an average score of $68.64 \%$ on this subscale. They were least knowledgeable concerning the pharmacological management of pain with an average score of $27.58 \%$ on this subscale, before completing the pain subject.

The expanded course cohort had post-test total scores ranging from 28 to 56 , with a mean of 43.41 correct out of 59 . Improvements in mean test scores occurred across all six subscales. As with the 1998 pilot, this expanded course sample had the largest improvement on the pharmacological management of pain subscale of the questionnaire, with an increase in mean score from 4.14 pretest to 6.46 post-test.

Comparing and combining the two cohorts

An analysis of variance (ANOVA) was used to compare the means of the subscale test scores for each cohort (trial) and from pre- to post-tests (time), as well as considering a three-factor interaction between subscale, trial and time. Both cohorts demonstrated significant improvement in scores from pre- to post-testing $(\mathrm{df}=461, \mathrm{~F}=14.10, \mathrm{P}<0.0001)$. Results revealed no significant differences between the subscales of the pilot cohort 
TABLE 6

Mean percentage correct, mean pretest scores, mean post-test scores and the SD for each of the sub-scales on the Revised Pain Knowledge and Attitudes Questionnaire for the pooled 1999 and 2000 expanded course sample

\begin{tabular}{|c|c|c|c|c|c|c|}
\hline & $\begin{array}{c}\text { Average \% Correct } \\
\text { (pretest) }\end{array}$ & $\begin{array}{c}\text { Mean } \\
\text { pretest scores }\end{array}$ & $\begin{array}{l}\text { pretest } \\
\text { SD }\end{array}$ & $\begin{array}{l}\text { Average \% correct } \\
\text { (post-test) }\end{array}$ & $\begin{array}{c}\text { Mean } \\
\text { post-test scores }\end{array}$ & $\begin{array}{l}\text { Post-test } \\
\text { SD }\end{array}$ \\
\hline Physiological basis of pain & 68.64 & 6.86 & 1.75 & 82.27 & 8.23 & 1.66 \\
\hline Psychological factors of pain perception & 63.96 & 8.96 & 2.54 & 74.35 & 10.41 & 1.50 \\
\hline Developmental changes in pain perception & 57.73 & 5.77 & 2.14 & 71.82 & 7.18 & 1.92 \\
\hline Assessment and measurement of pain & 35.91 & 3.59 & 1.89 & 42.73 & 4.27 & 1.70 \\
\hline Pharmacological management of pain & 27.58 & 4.14 & 2.88 & 43.03 & 6.46 & 2.88 \\
\hline Cognitive-behavioural Methods of pain relief & 54.09 & 5.41 & 1.73 & 68.64 & 6.86 & 1.17 \\
\hline Total for the R-PKAQ & 58.86 & 34.73 & 8.42 & 73.57 & 43.41 & 7.18 \\
\hline
\end{tabular}

R-PKAQ Revised Pain Knowledge and Attitudes Questionnaire

TABLE 7

Odds ratios and their $95 \%$ confidence intervals for each subscale

\begin{tabular}{|c|c|c|c|c|c|c|}
\hline & \multicolumn{3}{|c|}{ Post vs pretest } & \multicolumn{3}{|c|}{ Expanded course vs pilot } \\
\hline & Lower & OR & Upper & Lower & OR & Upper \\
\hline Physiological basis of pain & 1.05 & 1.74 & 2.86 & 0.43 & 0.71 & 1.17 \\
\hline Psychological factors of pain perception & 1.18 & 1.78 & 2.68 & 0.41 & 0.63 & 0.97 \\
\hline Developmental changes in pain perception & 0.92 & 1.41 & 2.16 & 0.47 & 0.75 & 1.19 \\
\hline Assessment and measurement of pain & 1.08 & 1.61 & 2.39 & 0.53 & 0.85 & 1.36 \\
\hline Pharmacological management of pain & 1.30 & 1.82 & 2.54 & 0.53 & 0.82 & 1.25 \\
\hline
\end{tabular}

OR odds ratio

and the expanded course cohort $(\mathrm{P}=0.065)$, and no significant interaction effect between the three factors $(\mathrm{P}=0.91)$.

To test the hypothesis that the students, performances (measured as the proportion of correct items) changed, a logistic regression model included the subscale as a factor and the pretest score as a covariate, as well as a subscale by pretest score interaction term. To incorporate possible correlations between students' performances across the subscales, the model included a random term for students. This generalized linear mixed model was fitted using a Penalized Quasi-Likelihood routine provided with the Modern Applied Statistics package (19) for the statistical program R (18). Results generally support the ANOVA findings, although students' knowledge of the psychological factors of pain perception $(\mathrm{df}=461, \mathrm{t}=-2.05$, $\mathrm{P}=0.04$ ) and cognitive-behavioural methods of pain relief $(\mathrm{df}=461, \mathrm{t}=-2.64, \mathrm{P}=0.008)$ were found to differ significantly between the two cohorts, with students performing worse in the expanded cohort group. In addition, significant improvement in knowledge postcourse was found in five of the six subscales measured, regardless of course. This sample demonstrated increased knowledge of the physiological basis of pain $(\mathrm{df}=461, \mathrm{t}=2.12, \mathrm{P}=0.03)$, assessment and measurement of pain $(\mathrm{df}=461, \mathrm{t}=2.27, \mathrm{P}=0.02)$, psychological factors of pain perception $(\mathrm{df}=461, \mathrm{t}=2.68, \mathrm{P}=0.007)$, cognitive-behavioural methods of pain relief $(\mathrm{df}=461, \mathrm{t}=2.05, \mathrm{P}=0.04)$ and pharmacological management of pain $(\mathrm{df}=461, \mathrm{t}=3.41, \mathrm{P}=0.0007)$. Students' knowledge of developmental changes in pain perception did not increase significantly, regardless of whether they were in the pilot or the expanded course.
The odds ratios (Table 7) show the odds of improving student performance from pre- to postcourse, as well as from the pilot to the expanded courses. The largest odds ratio increase from pre- to postcourse was seen for the pharmacological management of pain subscale, increasing the probability of a correct answer by approximately one and four-fifths times the probability of answering the item correctly before the elective. Note that the CI for the developmental changes in pain perception subscale includes the number one, reflecting the nonsignificant result using the logistic regression described above. Although the result was not significant, this finding still suggests that students were 1.4 times, or $40 \%$, more likely to score correctly on the post- than on the preassessment and measurement of pain subscale. Overall, students demonstrated an increase of $13.83 \%$ in the mean final score on the R-PKAQ, and statistically significant gains in five of six domains of pain knowledge. As can be seen, all CIs for all subscales of the expanded versus pilot courses include the number one, again reflecting the nonsignificant result using the logistic regression described above.

This model represents a more general form of the oneparameter item response on the Rasch (20) model. In general, the physiological and psychological subscales were the least difficult subscales for students, followed by the cognitive and developmental subscales, with the pharmacological and assessment and measurement of pain subscales being the most difficult. The odds ratios in Table 7 indicate that these subscale difficulties were generally consistent across tests and courses except that the expanded course students found the cognitivebehavioural subscale more difficult than the pilot cohorts. 


\section{DISCUSSION}

Completion of the elective pain course, based on the IASP curriculum for students of occupational and physical therapy, appeared to improve pain knowledge among students as measured by the R-PKAQ. These improvements were demonstrated regardless of whether the course was delivered in basic lecture format or in an expanded format including student seminars. More specifically, pain knowledge increased significantly in the following areas: pharmacological aspects of pain, physiological aspects of pain, assessment and measurement of pain, cognitive-behavioural methods of pain relief and psychological issues in pain. Although improvement in the developmental changes in pain perception subscale was obtained, it did not reach significance. These results are pleasing because the subscales of the R-PKAQ reflect important dimensions of the pain experience that have relevance for all members of the multidisciplinary team.

As might be expected in a school of health and rehabilitation sciences, students consistently found the physiological subscale the easiest of the six subscales, and the pharmacological subscale to be the hardest across both assessment times. Performance on these two subscales attained only a mild and nonsignificant correlation overall.

Given the lack of a control group in this study, it is not possible to say conclusively that the improvement in knowledge of pain among participants was due to course participation. Of note, participation in the expanded course was associated with a failure of students to improve in the areas of psychological issues in pain and cognitive-behavioural methods of pain relief relative to participation in the shorter course. This result needs to be considered in light of the fact that students in the smaller course obtained precourse scores that reflected greater knowledge in all pain domains.

The results also need to be viewed in light of the low response rate. The need for students to identify their questionnaires before handing them in to enable matching may have lessened the response rate. Twenty-two students handed in their questionnaires without an identifier to enable matching from pre- to postcourse. Additionally, the second questionnaire was completed in the last week of the semester when attendance was diminished due to multiple assessment completion demands. Furthermore, while the students' pain knowledge improved after the completion of the pain elective, no consideration was made for the students' prior experience with people with pain, whether on fieldwork, familial experience or other involvement.

Finally, it is acknowledged that the tool used in this study, the R-PKAQ, is in its infancy. This questionnaire was regarded as an appropriate one for the purposes of this study because other pain knowledge instruments tend to be discipline-specific or have been designed for use with people with pain (8). Previous findings suggest that the questionnaire would benefit from further revision and development (8, unpublished data). Results of the present project support this recommendation, with the suggestion that the subscales may be more highly correlated than is desirable. However, in support of the questionnaire is the finding of the item response model that students improved consistently across pre- and post-tests, and over both courses. This reinforces the validity and repeatability of the
R-PKAQ. It would be of interest to conduct an item analysis of the subscales with a large sample.

A number of investigations in the field have demonstrated marked improvement in students' knowledge about pain following the implementation of a specialized pain course $(8,14)$. The results of this project support such findings. However, while much of the current undermanagement of patients with pain problems has been associated with poor knowledge of pain issues among health professionals, the impact of improved pain knowledge of health care professionals on the management of patients with pain problems remains unclear. It will be necessary to follow up practising therapists who have completed pain education to the standards set out in the IASP curriculum to demonstrate the importance of a more pain-literate health professional population in reducing the severe human and social costs associated with pain.

\section{REFERENCES}

1. Ad Hoc Committee OT/PT Pain Curriculum (1994). Pain curriculum for students in occupational therapy or physical therapy. IASP Newsletter. Seattle: International Association for the Study of Pain, 1994.

2. Melzack R, Wall PD. Pain mechanisms: A new theory. Science 1965;150:971-6.

3. Brennan-Hunter AL. Children's pain: A mandate for change. Pain Res Manage 2001;6:29-39.

4. Liebeskind J, Melzack R. The International Pain Foundation: Meeting a need for education in pain management. J Pain Sympt Manage 1988;3:131-2.

5. Watt-Watson JH. Nurses' knowledge of pain issues: A survey. J Pain Sympt Manage 1987;2:207-11.

6. Loper K, Butler S, Nessly M, Wild L. Paralysed with pain: The need for education. Pain 1989;37:315-6.

7. Rochman DL. Students' knowledge of pain: A survey of four schools. Occup Ther Int 1998;5:140-54.

8. Unruh A. Teaching student occupational therapists about pain: A course evaluation. Can J Occup Ther 1995;62:30-6.

9. Strong J, Tooth L, Unruh A. Knowledge about pain among newly graduated occupational therapists: Relevance for curriculum development. Can J Occup Ther 1999;66:221-8.

10. Turnquist KM, Engel JM. Occupational therapists' experiences and knowledge about pain in children. Phys Occup Ther Paeds 1994;14:35-51.

11. Scudds R, Solomon P. Pain and its management: A new pain curriculum for occupational therapists and physical therapists. Physiother Can 1995;47:77-8.

12. Lebovits A, Florence I, Bathina R, Hunko V, Fox M, Bramble C. Pain knowledge and attitudes of health care providers: Practice characteristic differences. Clin J Pain 1997;13:237-43.

13. Kaasalainen V, Vainio A, Ali-Melkkila T. Developments in the treatment of cancer pain in Finland: The third nation-wide survey. Pain 1997;70:175-83.

14. Wilson J, Brockopp G, Kryst S, Steger H, Witt W. Medical students' attitudes towards pain before and after a brief course on pain. Pain 1992;50:251-6.

15. Sessle B. President's message. International Association for the Study of Painf Newsletter. Seattle: International Association for the Study of Pain, 1999; Fall.

16. Poyhia R, Kalso E. Pain related undergraduate teaching in medical facilities in Finland. Pain 1999;79:121-5.

17. International Association for the Study of Pain Ad Hoc Committee for the Occupational Therapy or Physical Therapy Pain Curriculum. Pain curriculum for students in occupational therapy or physical therapy. International Association for the Study of Pain Newsletter. Seattle: International Association for the Study of Pain, 1994.

18. Ihaka R, Gentleman RR. A language for data analysis and graphics. J Comp Graph Stat 1996;5:299-314.

19. Venables WN, Ripley BD. Modern Applied Statistics with S-PLUS. New York: Springer-Verlag Inc, 1999:229-314.

20. Rasch G. An item analysis which takes individual differences into account. Br J Math Stat Psychol 1966;19:49-57. 


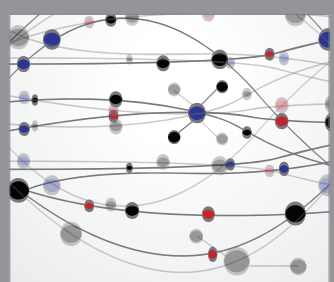

The Scientific World Journal
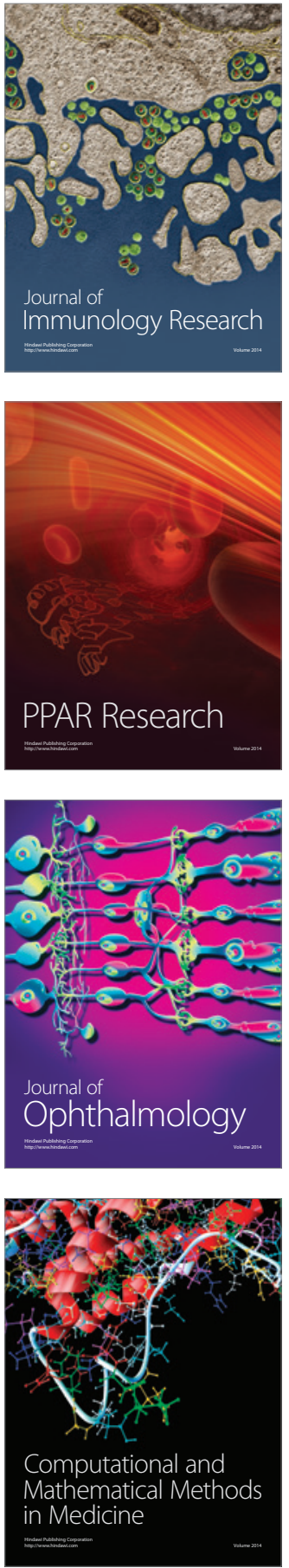

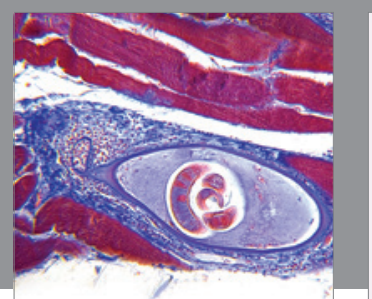

Gastroenterology Research and Practice

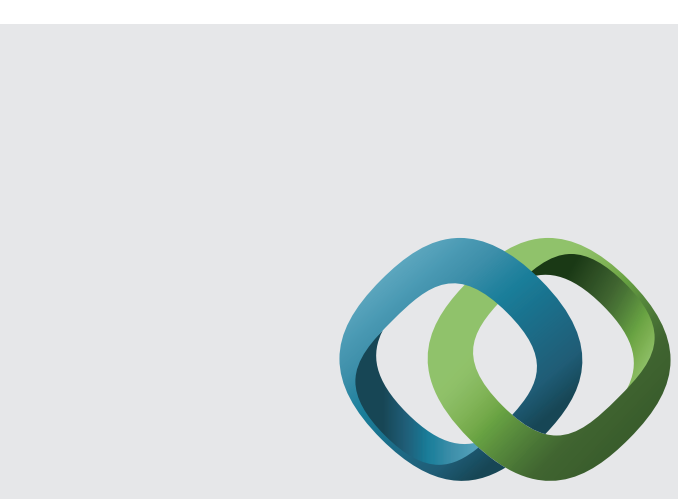

\section{Hindawi}

Submit your manuscripts at

http://www.hindawi.com
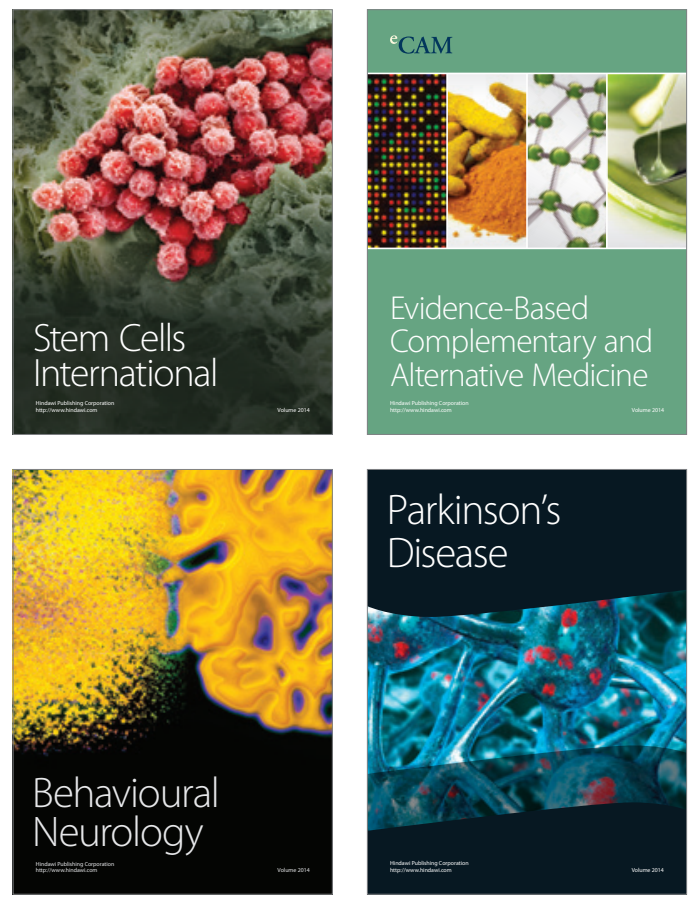
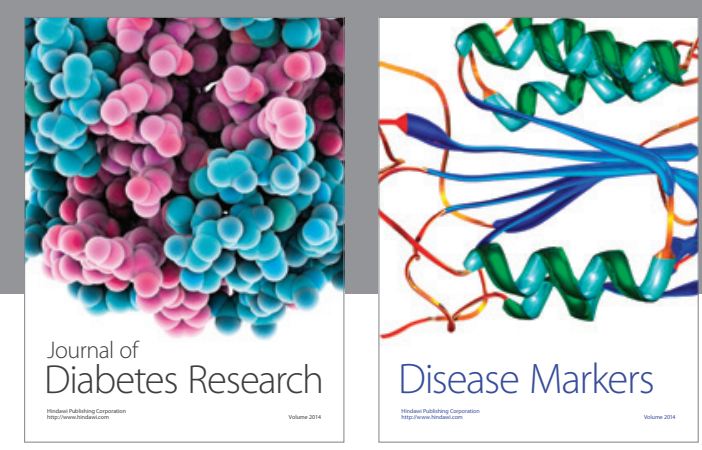

Disease Markers
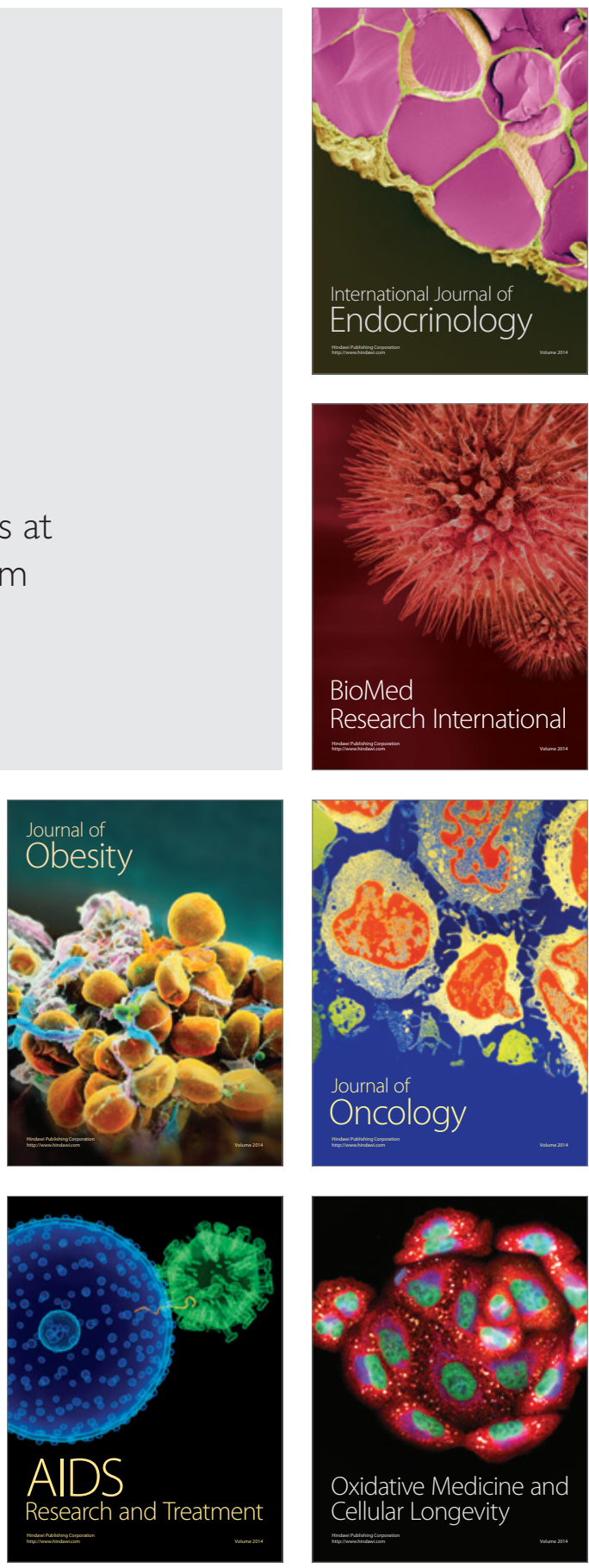